\title{
Los ajustes razonables: Estrategia de inclusión laboral para las personas con diversidad funcional en Colombia
}

\section{The Reasonable Adjustments: Labor Inclusion Strategy for People with Functional Diversity in Colombia}

\author{
DOI: https://doi.org/10.17981/juridcuc.17.1.2021.01
}

Fecha de Recepción: 2020/02/17 Fecha de Aceptación: 2020/08/06

Kelly Viviana Aristizábal Gómez

Universidad Sergio Arboleda. Santa Marta (Colombia)

kelly.aristizabal@usa.edu.co

Orlando Rodríguez Buenahora $\odot$

Universidad Sergio Arboleda. Santa Marta (Colombia)

orlando.rodriguezb@correo.usa.edu.co

\author{
Victoria Andrea Blanquiceth Ulloa 누 \\ Universidad Sergio Arboleda. Santa Marta (Colombia) \\ victoria.blanquiceth@correo.usa.edu.co
}

Para citar este artículo:

Aristizabal, K., Rodríguez, O. y Blanquiceth, V. (2021). Los ajustes razonables: Estrategia de inclusión laboral para las personas con diversidad funcional en Colombia. Jurídicas CUC, 17(1), 9-42. DOI: http:// dx.doi.org/10.17981/juridcuc.17.1.2021.01

\section{Resumen}

La discriminación y la desigualdad en las oportunidades y condiciones laborales son evidentes en el ámbito del trabajo. Específicamente, los derechos laborales de las personas con diversidad funcional son vulnerados por la sociedad incapacitante, que crea para ellos obstáculos físicos y actitudinales que generan la discapacidad. Frente a lo anterior, el modelo social enfocado en derechos y las acciones afirmativas son aspectos fundamentales para lograr la inclusión laboral de las personas con diversidad funcional. Debido al escaso y desorganizado desarrollo jurídico y doctrinal de los ajustes razonables en Colombia, se trazó el objetivo general de esta investigación, que fue establecer su alcance jurídico en los puestos de trabajo para las personas con diversidad funcional en Colombia. Para lograrlo, se hizo una revisión bibliográfica de fuentes nacionales e internacionales, interpretación de normatividad jurídica y análisis jurisprudencial en el ámbito nacional relacionada con el tema mencionado, como parte del método documental y del enfoque cualitativo. Como resultados, se estableció el alcance, que comprendió su concepto, clasificación según el tipo de discapacidad y sus límites. Para finalizar, Colombia tiene un deber constitucional de garantizar la inclusión laboral de las personas con diversidad funcional, sujetos de derechos y de especial protección constitucional, con respaldo de la Convención sobre los Derechos de las Personas con Discapacidad. Pues bien, los ajustes razonables no son concesiones especiales, sino más bien, un deber para la sociedad de conocer, aplicar y, en consecuencia, respetar los derechos humanos de las personas con diversidad funcional.

Palabras clave: Acción afirmativa: ajustes razonables: derechos humanos: discapacidad: diversidad funcional: inclusión laboral

\begin{abstract}
Discrimination and inequality in employment opportunities and conditions are evident in the workplace. Specifically, the labor rights of people with functional diversity are violated by the disabling society, which creates for them physical and attitudinal obstacles that generate disability. Faced with the above, the social model focused on rights and affirmative actions are fundamental aspects to achieve the labor inclusion of people with functional diversity. Due to the scarce and disorganized legal and doctrinal development of reasonable accommodations in Colombia, the general objective of this research was outlined, which was to establish its legal scope in the jobs for people with functional diversity in Colombia. To achieve this, a bibliographic review of national and international sources, interpretation of legal regulations and jurisprudential analysis at the national level related to the aforementioned topic was carried out, as part of the documentary method and qualitative approach. As a result, the scope was established, which included its concept, classification according to the type of disability and its limits. Finally, Colombia has a constitutional duty to guarantee the labor inclusion of people with functional diversity, subjects of rights and special constitutional protection, with the support of the Convention on the Rights of Persons with Disabilities. Well, reasonable accommodations are not special concessions, but rather, a duty for society to know, apply and, consequently, respect the human rights of people with functional diversity.

Keywords: Affirmative action: discapacity: functional diversity: human rights: labor inclusion: reasonable adjustments
\end{abstract}




\section{INTRODUCCIÓN}

Alrededor del mundo se han creado diferentes instrumentos jurídicos, de orden interno y externo, los cuales propenden el desarrollo de aspectos claves para la construcción de una sociedad pacífica, tolerante, respetuosa y armónica, entre ellos están los derechos humanos. Ha sido de gran importancia propender por la protección y garantía de los derechos fundamentales que posee cualquier ser humano, por el hecho de ser persona. Tan relevante ha sido la búsqueda por mejorar el tratamiento a los derechos humanos, que se ha extendido una protección legal especial a la naturaleza, a animales, a ríos, etcétera. Estos últimos se han dado por su estrecha relación con otros derechos que conciernen a la especie humana, como el de derecho a un ambiente sano o el de la protección por los recursos naturales.

Pues bien, en ese marco de protección jurídica de los derechos humanos se destaca aquel que cobija a los colectivos de personas con discapacidad, que son unos de los grupos de personas que, por sus condiciones de vulnerabilidad ante las características actuales de sus contextos sociales, ven afectados el cumplimiento de sus derechos fundamentales en las diferentes dimensiones de su cotidianidad. Las personas con diversidad funcional es una forma de referirse a un colectivo de individuos, que, a pesar de tener una afectación de tipo físico, psicosocial, sensorial o intelectual, incluso, múltiple, conserva otras competencias, aptitudes o habilidades que le permiten desarrollarse en su medio. Este último, resulta de priorizar la falta de adaptación de la sociedad a las realidades comunes que en ella viven sus diferentes miembros.

Por lo anterior, se hace necesario prestar atención a aquellas dificultades que se les genera a algunas personas en situaciones particulares por no contemplar diseños universales, accesibles e incluyentes ante la diversidad que no exige, sino que reclama condiciones justas y no discriminatorias. Pero, para este trabajo de investigación cobra especial importancia el ámbito laboral, contexto en el cual las personas con diversidad funcional se ven inmersas por 
la necesidad humana de conseguir el sustento para su supervivencia. En él se pueden presentar situaciones que ocasionan un trato excluyente y discriminatorio hacia este colectivo debido a su discapacidad, lo cual puede deberse a diferentes razones, por nombrar algunas, están: el desconocimiento ante la discapacidad; la falta de capacitación al sector empresarial sobre cómo adecuar su empresa de forma inclusiva; poca humanidad frente a seres humanos que llegan a ser vistos como cargas o inútiles.

$\mathrm{Al}$ respecto, existen diversas acciones que permiten hacer material el derecho al trabajo de la colectividad en mención, en especial la que será motivo de desarrollo en el presente artículo; se trata de los ajustes razonables. No solo se convierte en una acción afirmativa, con relevancia y desarrollo mundial, sino también, una estrategia de inclusión laboral. Se trata de modificar aquel contexto que está ambientado para quienes en él pueden desenvolverse sin ninguna adversidad que les genere dificultades, pero que no tiene en cuenta la diversidad de personas y sus diferentes situaciones que, al interactuar dentro de él, se verán limitados. En el ámbito laboral se requieren de ambientes incluyentes, que posibiliten el desarrollo eficiente de las actividades de los trabajadores, sin que haya obstáculo por falta de herramientas, conocimiento sobre la situación en la que se encuentra el trabajador, o porque la empresa o el puesto del trabajo no tiene las condiciones óptimas para el trabajador.

En ese sentido, los ajustes razonables constituyen la manera en la cual se va a atender de forma efectiva a la discapacidad, según los diversos tipos que existen. Con ello, el trabajador podrá cumplir con sus funciones dentro de la empresa a la cual se encuentre vinculado. Además, como consecuencias se logra proteger sus derechos fundamentales a la vida digna, al trabajo, a la igualdad, a la no discriminación, a la salud y seguridad social, etcétera. No obstante, en Colombia aún resulta ser un tema que está en desarrollo académico más que jurídico. Por esto último, se requiere de la precisión del alcance jurídico de los ajustes razonables, para que permita un mejor conocimiento, y posterior aplicación, de esta acción afirmativa dentro de la empresa. 
De esta manera, se desarrolló el presente artículo teniendo en cuenta la siguiente pregunta problema: ¿Cuál es el alcance jurídico de los ajustes razonables en los puestos de trabajo para las personas con diversidad funcional en Colombia? Se formuló de cara al ámbito donde situamos el estudio de los ajustes razonables, este es, el laboral. Además, el alcance jurídico es fruto de las inquietudes que se generan al ahondar en el ordenamiento jurídico colombiano, donde no hay un desarrollo compilado, organizado y especial del tópico del presente artículo. Ahora bien, para llegar a su resolución, como acto seguido, se formuló el objetivo general que guiaría la realización de esta investigación, el cual fue: Establecer el alcance jurídico de los ajustes razonables en los puestos de trabajo para las personas con diversidad funcional en Colombia. Y, como complemento necesario al anterior objetivo, se precisaron tres objetivos específicos, los cuales fueron: Primero, precisar el concepto de ajuste razonable según el modelo social enfocado en derechos; segundo, identificar algunos ajustes razonables según una clasificación de la discapacidad; por último, presentar el nivel de desarrollo jurídico de los ajustes razonables en Colombia, tanto normativa como jurisprudencialmente.

Esta investigación es de tipo jurídico con un enfoque cualitativo, cuyo alcance es descriptivo. Además, el método a usar es documental con un nivel descriptivo. Se usaron fuentes primarias y secundarias, de la siguiente manera: Se realizó interpretación y análisis de normas jurídicas y jurisprudencia nacional e internacional; de igual forma, se realizó una revisión de obras académicas, nacionales e internacionales, la cual está soportada en resúmenes analíticos de investigación.

\section{Desarrollo}

Los ajustes razonables han tenido un desarrollo continúo a nivel internacional, para nombrar algunos países que lo han hecho se tienen los siguientes: Estados Unidos, España, Chile, Perú y México, entre otros. Pues bien, debido a ello se hace pertinente conocer de esos avances para que sean un aporte fundamental en el desarrollo de este dentro de Colombia, en especial, a nivel jurídico. Desde 
la Constitución Política de Colombia de 1991 se propende por la protección a la dignidad humana, para lo cual es importante la salvaguarda y garantía de los demás derechos fundamentales. El derecho al trabajo, artículo 27 superior, por su parte, con amparo constitucional, pero también internacional, es decir, desde el bloque de constitucionalidad, representa uno de los derechos fundamentales que permiten la protección consecuente de otros de la misma categoría, como la vida digna, el mínimo vital, la salud y la seguridad social, entre otros.

Frente a la relevancia de la protección de los derechos de las personas, las diferentes problemáticas sociales, políticas y económicas se convierten en obstáculos férreos para lograr la materialización del ordenamiento jurídico interno colombiano, como aquellos instrumentos de índole supranacional. Ahora, especial atención merece, para efectos de este trabajo, un colectivo cuya característica principal es la discapacidad, que no es más que el resultado vano de la interacción entre estos individuos con diversidad funcional y la sociedad inadaptada y nada preparada frente a la pluralidad de personas que la conforma.

Es la discapacidad un tema que ha sido de interés no solo social sino, también, jurídico. En el ordenamiento legal vigente de Colombia se han logrado avances en cuanto a la protección y garantía de los derechos de las personas con diversidad funcional, indistintamente de la afectación que presenten, como lo constituye la Ley 1996 (2019). A través de la norma mencionada, se eliminan figuras jurídicas como la interdicción, elemento relacionado con las históricas creencias falsas que rodean a las personas con diversidad funcional. Por lo anterior, desde el campo de acción del derecho, de la investigación sociojurídica y desde las ciencias sociales se puede aportar al desarrollo de la ley, a través de su contextualización en lo social, y no solo en lo meramente legal. Con la investigación documental acerca de los ajustes razonables, se da paso a crear información organizada y pertinente sobre una acción afirmativa que abre paso a la inclusión laboral, en una sociedad donde el sector empresarial requiere del conocimiento y capacitación sobre la inclusión dentro de sus empre- 
sas, el uso de herramientas y mecanismos que la materialicen y una humana visión sobre su entorno, para crear sociedad, justa y con condiciones dignas.

Breve aproximación a los modelos o paradigmas que han definido a la discapacidad

Resulta pertinente traer a colación que el concepto de discapacidad ha sido definido de diferentes formas a lo largo de la historia, Dichos conceptos se han encuadrado dentro de unos modelos o paradigmas que, incluso con el transcurrir del tiempo, mantienen rezagos de sus obsoletos y poco inclusivos postulados. El continúo desarrollo del derecho a nivel mundial ha permitido vislumbrar una sociedad más incluyente. El objetivo deberá ser permear la conciencia de la sociedad, para llegar a materializar desde el derecho la vida digna y en condiciones justas y humanas que se pregona en la norma jurídica. Por consiguiente, se ha logrado construir nuevas perspectivas sobre la discapacidad, novedosas formas de entenderla y mejores mecanismos para cerrar brechas de desigualdad por ella.

Al respecto, se debe empezar por el modelo de prescindencia, el cual concebía a la discapacidad como un castigo divino, que podría ser aviso de unos peores. Estuvo presente en la época antigua y medieval, pero su incidencia permanece hasta en la actualidad. Para la época de la Antigua Grecia y Roma, este modelo generó la ejecución de prácticas inhumanas, justificadas en la prevención no solo de castigos de los dioses, sino también, por una raza sin ese tipo de características. Tiempo después, en la época medieval, la concepción de la discapacidad mermó en su influencia al dejar de realizar asesinatos debido a esa situación, supliendo esa idea por la de que era el producto de la obra del diablo o de la brujería. La consecuencia de esta manera de considerar a la persona que se encontraba en esta situación, eran dos: por un lado, el submodelo eugenésico, desembocaba en prácticas severas como el infanticidio; mientras que el submodelo de marginación generaba segregación de la persona de la sociedad en la cual fuera miembro (Palacios, 2008). 
El siguiente paradigma de la discapacidad fue el modelo médicorehabilitador, o médico-biológico. A decir verdad, no implicó un avance como tal, pues aún se generaba la exclusión de las personas con diversidad funcional, puesto que al no considerarse a estos como personas con capacidades como cualquier otro de su entorno social, entonces se les privó del ejercicio de sus derechos en condiciones iguales a los demás. Lo anterior se justificó porque las personas con discapacidad estaban enfermas, situación que debía normalizarse o rehabilitarse. Hasta tanto no se haga lo anterior, ese individuo estaría restringido del ejercicio digno y adecuado de sus derechos, como, por ejemplo, el de la capacidad legal (Lermen, Martínez y Parra, 2013). Cabe anotar que, en Colombia, a las personas que eran declaradas judicialmente como interdictos, es decir, que tenían discapacidad absoluta, eran restringidas de su capacidad de ejercicio, como para celebrar negocios jurídicos, por la necesidad de estar representados extra y judicialmente. Esta situación cambió con la promulgación de la Ley 1996 (2019), que reguló el régimen de la capacidad legal de las personas con discapacidad mayor de edad. Se trató de un cambio a nivel nacional de normas cuya esencia seguía perpetuando la concepción médica y rehabilitadora de personas que, aunque con afectaciones en su capacidad mentales o cognitivas, podrían darse a entender, manifestar su voluntad, en otras palabras, ejercer sus derechos como cualquiera. Por lo anterior, se buscaron formas para que ello fuera posible; precisamente los ajustes razonables fueron uno de ellos, junto a los apoyos, transitorios o permanentes, según sea el caso.

Más adelante, apareció el denominado modelo social, el cual sí puede considerarse como un avance en cuanto al tratamiento de la discapacidad en aquellos países que acuñaron dicho paradigma. A través de este se dejó de lado las anteriores concepciones, para darle paso a entender que la discapacidad es un concepto que surge por las barreras físicas o actitudinales que la generan. La sociedad se convierte en la incapacitante del sujeto que presenta una afectación de alguna forma a nivel físico, o mental, por manejarlo de forma sencilla (Bolaños, 2015). El mencionado modelo tomó auge con la Convención 
sobre los Derechos de las Personas con Discapacidad, instrumento jurídico derivado de la Organización de las Naciones Unidas (ONU, 2006), la cual Colombia aprobó para ese mismo año, pero lo adoptó, posteriormente, con la Ley 1346 (2009). Este instrumento internacional fue el primero del siglo XXI en materia de derechos humanos, que, a partir de entonces, ha sido el mecanismo más importante para el quince por ciento (15\%) de la población mundial, por situar a la discapacidad en el marco jurídico de los derechos humanos (Comisión Nacional de Derecho Humanos de México-CNDH México, 2018).

Aunque, más allá del modelo social, surge con el paso de los años un paradigma más desarrollado, que se le denomina en la literatura académica internacional, como el modelo social enfocado en derechos. En este, se pretende ir más allá de un marco jurídico proteccionista y garantista de los derechos fundamentales de las personas con diversidad funcional, sino que, busca una concientización social que genere inclusión de forma real y efectiva, en todas las esferas de la vida de estos individuos (Gutiérrez, 2018).

Finalmente, el modelo de diversidad funcional, cuyo término acuñamos en el presente documento para referirnos a las personas en situación de discapacidad, aparece como el modelo más reciente de la discapacidad, cuyos planteamientos se fundamentan en el respeto por la dignidad humana, la libertad y autonomía y el derecho a la igualdad para las personas con diversidad funcional. Para lograrlo se hace necesario aplicar un diseño universal que permita lograr la accesibilidad del mayor número de personas posible. Así pues, se trata de entender que la diversidad es parte de la misma especie humana, porque las diferencias surgen desde el nacimiento e, igualmente, aparecen otras a lo largo de la vida (Araque y Suárez, 2017).

\section{Diferenciación entre minusvalía, discapacidad e incapacidad}

El lenguaje puede ser usado de diversas maneras, en especial, expresar pensamientos o sentimientos a través de la palabra. Se debe tener en cuenta que la palabra no es la única forma de comunicarse, pero para efectos de este apartado se resalta el uso que se puede hacer de ella. Es de relevancia destacar que, en una sociedad 
global, como se caracteriza la sociedad del siglo XXI, se requieren de estrategias para limitar la libertad de expresión y el desarrollo de la libre personalidad. Al respecto, las creencias equivocadas sobre las personas con diversidad funcional pueden conllevar al uso de connotaciones o adjetivos calificativos que los tratan de caracterizar y describir, pero de forma despectiva, peyorativa y discriminatoria.

A pesar de las dificultades que se han mantenido en la historia de llevar a un desarrollo adecuado el lenguaje inclusivo y, para efectos de este artículo, de un lenguaje legislativo digno e inclusivo, se han logrado avances en ese sentido. A través de los medios masivos de comunicación y de las herramientas tecnológicas que este mundo globalizado de hoy ofrece se puede propagar una concepción adecuada de lo que es implica la discapacidad, y la diversidad funcional. Es por esto por lo que se requiere de hacer una precisión sobre palabras relacionadas con la discapacidad, pero que son distintas, al menos desde la mirada jurídica del derecho colombiano.

Así, el lenguaje, teniendo en cuenta los planteamientos de Van (2003), puede llegar a ser utilizado como un medio, en otras palabras, un canal de manifestación o expresión de ideas, sentimientos, prejuicios, conceptos discriminatorios, etcétera. Se trata, entonces, de comprender que hay formas adecuadas en las cuales referirse a un individuo o colectivo. Una forma inclusiva de referirse a las personas con diversidad funcional es como la que resaltan Yupanqui, González, Llancalahuén, Quilodrán y Toledo (2016), la cual corresponde a una persona con discapacidad. En concordancia con ello, en Colombia se ha adoptado por el máximo tribunal constitucional de la nación a persona en situación de discapacidad como manera inclusiva, respetuosa con la dignidad humana y no discriminatoria, en la cual referirse a una persona con diversidad funcional (Sentencia C-043, 2017). En dicho pronunciamiento, la Corte trae a colación la hipótesis formulada por los fundadores de la etno-lingüística, Edward Sapir y Benjamín Lee Whorf, que se denomina la hipótesis de Sapir-Whorf, difundida en 1956, de la cual se trae a colación solo el siguiente aparte: “[...] 1) El lenguaje es un producto social que configura nuestra forma de aprehensión del mundo que nos rodea 
[...]". A partir de lo anterior, se puede llegar a inferir que, si se adecúa el lenguaje, a uno constitucionalmente válido, es decir, que no sea discriminatorio y que esté acorde con el respeto de la dignidad humana, entonces, podrá la sociedad, de forma natural, adoptarlo dentro de sí, cada uno de sus miembros, hasta consolidar, para el caso de las personas con diversidad funcional, a la discapacidad como distinta a la discapacidad o a la minusvalía.

En esta misma línea, la Corte Constitucional ha realizado estudios, análisis y precisiones en torno al tópico de la discapacidad en Colombia. Ha establecido la distinción que debe hacerse entre los conceptos de discapacidad, minusvalía e invalidez. Sobre los dos primeros hizo hincapié, en la Sentencia T-933 (2013), donde la minusvalía está inmersa en la discapacidad, por consiguiente, puede entenderse como aquella condición en la cual el individuo, a pesar de sus diversas competencias y aptitudes, no puede ejercitar sus derechos en igualdad de condiciones, toda vez que la sociedad en la que se encuentra no ha desarrollado procesos adaptativos e incluyentes que les permitan el desarrollo de sus necesidades y aspiraciones.

Por otro lado, sobre la invalidez, la Corte Constitucional, en la misma sentencia anterior (Sentencia T-933, 2013), expresó que es un término que alude a la prestación de ley que se le otorga a aquella persona que cumpla con los requisitos legales para ello, como que se le declare la pérdida de la capacidad laboral en un cincuenta por ciento (50\%) o superior a este porcentaje.

Por último, cabe especificar que el máximo tribunal constitucional de Colombia comparte el modelo social de la discapacidad y su forma de entender el concepto, por lo tanto, manifestó que "la discapacidad surge principalmente del fracaso de la adaptación del ambiente social a las necesidades y aspiraciones de las personas con discapacidad, no de la incapacidad de estas personas de adaptarse al ambiente" (resaltado del texto original, Sentencia T-933, 2013). Ahora, la discapacidad propiamente puede entenderse como un fenómeno multidimensional, que consiste en una disminución, deterioro o afectación en una función física, cognitiva, sensorial, intelectual, o de otra índole en una persona, situación que es comparada con 
el estándar o condición habitual de los demás miembros del grupo social donde se encuentra. Sus implicaciones van, teniendo en cuenta a la Clasificación Internacional del Funcionamiento, de la Discapacidad y de la Salud (CIF) de la Organización Mundial de la Salud, en su Resolución WHA54.21 (OMS, 2001), la cual establece tres dimensiones que abarca la discapacidad, estas son: "La estructura y función del cuerpo (deterioro del cuerpo), la actividad (restricciones de actividad) y la participación (restricciones de participación)" (Solano, 2019, p. 54). Es por lo anterior, que como se trata de un fenómeno complejo, con factores más sociales que del propio individuo en situación de discapacidad, se convierte en una problemática con importancia multisectorial, por ser un asunto de derechos humanos.

\section{Resultados}

El concepto de ajuste razonable en el marco

del modelo social de la discapacidad y su

diferencia con acción afirmativa y diseño universal

Debe hacerse la precisión de lo que se entiende por ajuste razonable a la luz del ámbito jurídico nacional e, incluso, desde el académico. Para precisar su concepto jurídico, se traen a colación pronunciamientos de la Corte Constitucional, como lo es la Sentencia C-293 (2010). En ella, la Corte Constitucional se pronunció frente a cómo debe entenderse los ajustes razonables, de la siguiente manera: “[...] concepto que se refiere a la extensión de las acciones que deberán adelantarse para mejorar las condiciones de accesibilidad, y con ello, el pleno ejercicio de los derechos de las personas discapacitadas [...]". En el anterior apartado se puede destacar dos aspectos: El primero, es el fin de los ajustes razonables, el cual es la mejoría de aquella situación desventajosa en la que se encuentra la persona con diversidad funcional, a través de la acomodación física de su espacio, para eliminar las dificultades propias de la falta de adaptación; y el segundo, es la esencia de los ajustes razonables, pues su implementación está fundada en el respeto por la dignidad de la persona con diversidad funcional, por ser sujeto de derechos. 
Para complementar lo anterior, se trae a cita lo dispuesto en la Convención sobre los Derechos de las Personas con Discapacidad, (ONU, 2006, art. 2), cuyo contenido literal es el siguiente:

Artículo 2. Definiciones. [...] Por “ajustes razonables" se entenderán las modificaciones y adaptaciones necesarias y adecuadas que no impongan una carga desproporcionada o indebida, cuando se requieran en un caso particular, para garantizar a las personas con discapacidad el goce o ejercicio, en igualdad de condiciones con las demás, de todos los derechos humanos y libertades fundamentales [...] (ONU, 2006, p. 4).

En relación con lo anterior, se debe hacer referencia al modelo social, especialmente al enfocado en derechos, que caracteriza a la convención en comento. Este documento consiste en el principal instrumento jurídico que vincula a sus Estados parte a realizar todas las acciones pertinentes para mejorar la calidad de vida de un colectivo históricamente marginado y vulnerado en sus derechos fundamentales, como es el de las personas con diversidad funcional. El concepto de ajuste razonable que presenta en el fragmento citado se enmarca, precisamente, en el modelo social. Esto mismo responde a la necesidad de hacer entender que la persona con discapacidad es hábil y que puede desempeñarse en un espacio cualquiera, siempre y cuando medien las condiciones que posibiliten su autónomo desenvolvimiento. Por lo cual, se trata de una acción afirmativa, que tiene un límite en la prevención de una posible carga desproporcionada o indebida, pero que, si se requiere, se debe hacer, porque su fin es el de proteger derechos humanos, libertades y garantías fundamentales.

Desde la literatura académica, se ha desarrollado el concepto de ajustes razonables con elementos muy similares a los del ámbito jurídico, como es el caso de Lermen et al. (2013), cuyos planteamientos en torno a esa acción afirmativa permite entenderla como aquellas adecuaciones que se implementan en una empresa para acomodar las necesidades de las personas con diversidad funcional. $\mathrm{Al}$ respecto debe hacerse una salvedad y es que, cuando se hace referencia a las necesidades de la persona con discapacidad, no se 
alude a una concesión arbitraria o caritativa, sino a una exigencia natural por la inadaptación del contexto laboral a una pluralidad de individuos y de situaciones.

Por otra parte, se debe hacer una distinción sobre palabras que se relacionan con los ajustes razonables, pero no son sinónimos de ella, sino que tienen estrecha relación debido al fin que comparten, salvaguardar derechos humanos de la sociedad en general. Así, conceptos como diseño universal y acción afirmativa son los que se traen a colación para su diferenciación con los ajustes razonables. En primer lugar, el diseño universal hace referencia a que, en la elaboración de estructuras físicas, programas tecnológicos, políticas públicas y demás tópicos de la sociedad se tenga en cuenta fines de inclusión social, es decir, que sea posible usarlos por cualquier persona, esté o no en una situación de discapacidad (Bolaños, 2016).

En otro lugar, las acciones afirmativas, las cuales están representadas como políticas o medidas que estén encaminadas a disminuir o erradicar la discriminación hacía un grupo o colectivo que ha sido víctima de ello históricamente; además, permite que dichos individuos subrepresentados logren una mayor representación (Sentencia T-933, 2013).

\section{Proceso de vinculación laboral para personas con diversidad funcional}

Para llegar a situar la atención en la discapacidad y su tratamiento dentro del puesto de trabajo, debe identificarse cómo debería ser el proceso de selección y vinculación laboral de la persona con diversidad funcional. Según Agudelo, Casas, Tovar y Villadiego (2017) en primer lugar, en la etapa de selección y contratación del sujeto con la discapacidad física; en segundo lugar, se deberán hacer adecuaciones que implican los ajustes razonables en materia física o de infraestructura; y por último, tendrá que trabajarse el ambiente psico-social de la empresa para generar una buena relación entre el sujeto en situación con discapacidad y sus compañeros de trabajo. Así pues, en cuanto a la etapa de selección y contratación del postulado al puesto de trabajo que esté en condición de discapacidad, 
se debe traer a colación las diferentes dependencias que conforman la empresa, entre ellas, se puede mencionar: talento humano, salud ocupacional, finanzas y contaduría y el área jurídica.

Es fundamental que haya un trabajo mancomunado entre los diversos sectores que conforman la empresa, por ejemplo, el área de gestión del talento humano deberá hacer un proceso de selección acorde a las competencias y aptitudes que presente la persona, en ese sentido, se evitará discriminar a los aspirantes por características como una condición de discapacidad. Asimismo, el área jurídica posibilita que el proceso de contratación y lo que tiene que ver con la relación empleador-trabajador se den de acuerdo con la normatividad vigente. Por supuesto, tratándose de una persona con diversidad funcional, el área jurídica debe velar porque haya un correcto proceso de inclusión laboral, donde se evite la discriminación o la vulneración a cualquiera de sus derechos. De esta manera, se entiende por ejemplo que en la etapa de la entrevista se deben evitar manifestaciones de victimización, lástima, compasión y sobrevaloración de las capacidades de la persona con diversidad funcional, para percibir adecuadamente las virtudes y debilidades que posee como cualquier otra persona (López et al., 2017). Por último, cabe anotar que el área de contaduría y finanzas proporcionará la orientación sobre cómo obtener los beneficios tributarios que se merecen los empleadores que vinculen a su planta de trabajadores a una persona con discapacidad, según lo establecido por la ley.

En este sentido, cobra relevancia resaltar el derecho a la estabilidad laboral reforzada, de rango constitucional, y con desarrollo como principio dentro del derecho laboral de Colombia. La Corte Constitucional lo ha extendido a ciertos grupos de personas con características que los hacen ser sujetos de especial protección constitucional, por lo cual cuentan con garantías que permitan establecer una seguridad en la continuidad del vínculo laboral que ha sido contraído. Por ende, cuando se despida sin justa causa a una persona en situación de discapacidad, se constituye un acto discriminatorio por parte del empleador, que el Estado debe de hacer cumplir por los medios legales con los que se cuenta en el país (Sentencia C-531, 2000). 
Clasificación de la discapacidad y algunos

ajustes razonables aplicables al puesto de trabajo

Pues bien, una vez hecho el contexto anterior, debe hacerse referencia a que la discapacidad trae consigo el concepto de diversidad, que abarca, entre otros aspectos, las diferentes afectaciones que puede llegar a presentar un individuo en sus diversas capacidades. Los tipos de discapacidad varían en algunos autores, sin embargo, se ha seleccionado la siguiente clasificación (Agudelo et al., 2017): Física, intelectual, psicosocial y sensorial. De igual forma, se debe resaltar que la afectación no será en todos los casos de un solo tipo, pues, por mención de instituciones estatales como el Servicio Nacional de Aprendizaje (SENA), la discapacidad múltiple también se puede presentar en un sujeto. Sobre lo anterior, se suma lo que expone Mahecha (2018), quien expresa que existen cinco tipos de discapacidades, expuestas de la siguiente manera: "[...] el SENA demuestra su compromiso con la inclusión de la población con discapacidad [...] brindando atención a las personas con discapacidad visual, auditiva y sordo-ceguera, física e intelectual". La relevancia de los ajustes razonables en este sentido es que pueden ser dispuestos para cada situación, o sea, adecuar el ambiente físico a como debe ser originalmente, pero que por no haberse tenido en cuenta un espacio accesible e incluyente, se adecúa a la persona que presente una determinada afectación.

Para continuar, se tratarán cada una de las discapacidades citadas. Para empezar, la discapacidad física, comprende aquella afectación en la movilidad y funciones motoras de la persona. En ese sentido, se hace necesario que haya la adecuación de la planta física de la empresa $y$, especialmente, del puesto de trabajo, de la persona con discapacidad física, de acuerdo con lo que presente. Así las cosas, se tiene en cuenta el poseer una silla de ruedas, al menos, dentro de los recursos propios de la empresa. Además, hay que tener presente que elementos como aquellos que sirven: 
[...] Para [...] el desplazamiento, el alcanzar objetos y el accionar mecanismos especiales [...] pasillos amplios con recorridos breves, puntos de descanso y apoyo, pasamanos y barandas, ascensores o escaleras eléctricas (si aplica), superficies de piso regulares y antideslizantes [...]. Para las personas [...] en silla de ruedas [...] espacios amplios que permitan maniobras necesarias de aproximación a cada puesto, rampas de suave pendiente, rampas para cambios de niveles, entre otros (Agudelo et al., 2017, p. 27).

Lo ideal es propiciar las condiciones para que la persona con afectación en su capacidad física pueda realizar sus actividades, movilizarse y cumplir con sus labores de la forma más independiente posible, esto permite la inclusión real y efectiva en el ámbito laboral. Aún más, la adaptación física de la empresa no solo es el único ajuste razonable que se puede llegar a hacer, debido a que el componente social en dicho lugar puede influir en la materialización de la inclusión laboral de la persona o en su obstaculización. Entonces, la capacitación al personal de la empresa sobre la discapacidad física evitará circunstancias como el crear un ambiente con paternalismos discriminatorios por exceso de protección a la persona con diversidad funcional.

El siguiente tipo de discapacidad es el sensorial, en la cual, la persona presenta pérdida en alguno de los sentidos, las más usuales son las afectaciones en la visión y la ceguera o sordera. Debe tenerse en cuenta que sea la discapacidad que fuere, se deben observar tres momentos, mencionados en su momento en el presente artículo. En primer lugar, un proceso de selección y vinculación adecuada de la persona que se postula para el puesto de trabajo. Lo anterior se refiere a que las diferentes dependencias de la empresa, como la de talento humano y la jurídica, harán un trabajo conjunto con la fundación o la institución de formación en el empleo (como es el caso del SENA) que esté a cargo de la persona con diversidad funcional. La idea es aplicar el sistema que se acomode a su discapacidad o a la afectación que presente en alguno de sus sentidos. Por ejemplo, si se da el caso de una persona con discapacidad visual, es conveniente aplicar el lenguaje braille para realizar la prueba que se le realiza 
en esa empresa a los aspirantes al cargo o puesto. Otro caso podría ser el de una persona con discapacidad auditiva, caso en el cual se puede usar la prueba de Wartegg (López et al., 2017).

Ahora, sobre las adecuaciones físicas que se deben realizar en la empresa, tratándose de una persona con discapacidad sensorial, Agudelo et al. (2017) presentan algunas que se podrían implementar, con el objetivo de que puedan realizar sus labores sin necesidad de depender de la asistencia permanente de alguien. Así, se pueden mencionar los siguientes:

[...] 3. Señalización de accesibilidad: Esta señalización se caracteriza por estar comprendido con un símbolo universal (S.I.A) está encargada de dar información sobre la accesibilidad del inmueble, indicando el acceso o la prioridad del acceso. 4. Señalización acústica: Esta señalización se acomoda, a una escala audible, fácil de identificar e interpretable. Antes de sonar se escuchará un sonido de atención. 5. Señalización Táctil: Esta señalización tendrá una fijación en el suelo, se facilitará mediante texturas rugosas, en pavimento, en alto relieve o sistema braille. Su ubicación será en pasamanos, mecanismos de control entre otros [...] (Agudelo et al., 2017, p. 38).

En efecto, según López et al. (2017) el aspecto físico de la empresa debe ser conocido por la persona con discapacidad visual, el cual se hace con una guianza para que pueda hacer el reconocimiento de los espacios, como de los riesgos que existen dentro del mismo entorno laboral. Finalmente, sobre el ambiente social-laboral, se hace necesario que las personas que rodean a estos sujetos en situación de discapacidad sensorial puedan conocer las reglas básicas, por medio de las cuales pueden interactuar de mejor manera, incluso ayudarles en lo que se deba.

En otro lugar, a partir de lo expuesto por Agudelo et al. (2017), se tiene a la discapacidad intelectual, que se relaciona con aquellas dificultades que se presentan en la capacidad de aprendizaje, de relacionarse o de desplegar conductas para la ejecución de actividades cotidianas. En la empresa donde labore una persona en esta situación deberá trabajar, en primera medida, en lo relacionado la 
adaptación del espacio social-laboral, debido a que esta discapacidad no requiere de modificaciones estructurales importantes, pero sí de un ambiente libre de paternalismos que desembocan en comportamientos discriminatorios. Pues bien, en un principio, en la etapa de selección y vinculación laboral deberá atenderse a las precisiones que haga la fundación o la institución educativa que conozcan el proceso formativo de la persona con discapacidad intelectual. Dichas indicaciones podrán versar sobre las competencias o aptitudes que tenga dicho individuo. Al tener en cuenta eso, en la siguiente etapa, se hará la asignación del puesto de trabajo de acuerdo con la información suministrada de la persona en situación de discapacidad intelectual.

Sumado a lo anterior, los ajustes razonables que necesitan deberán atenderse a los grados de discapacidad intelectual que existen, tal como lo plantean expertos en la materia como Ke y Liu (2017), quienes en su investigación traen a colación los siguientes grados: leve, moderada, grave y profunda. Frente a ellos se debe realizar un examen interdisciplinario entre profesionales de salud mental, como por juristas, para que establezcan si pueden acceder a un puesto de trabajo, la manera en la cual lo harán y aquellos recursos, ajustes, herramientas o apoyos legales y adecuados que requiera para realizarlo. Así, se trae a colación el Sistema de Comunicación Aumentativa y Alternativa, un tipo de apoyo, por medio del cual se pueden llegar a comunicar dichos individuos de una manera no tradicional. Sobre este sistema existen aplicaciones de celulares y programas de computador de fácil acceso, aplicación y adquisición por parte del empleador para con el trabajador con discapacidad intelectual, tales como lo es la aplicación móvil LetMeTalk: Talker SAAC/CAA/SAC (versión 1.4.29).

Por último, la discapacidad psicosocial, la cual hace referencia a aquella "inhabilidad", tal como lo expresan Agudelo et al. (2017), para relacionarse en el medio social de la manera en la cual se acepta. Además, presentan cambios de humor, forma de pensar y de actitud, lo que genera problema a la hora de interactuar con quienes los rodean. En cuanto al trato a esta discapacidad en la empresa, 
se hace necesario, como lo exponen los autores mencionados, que haya una selección y colocación correcta del individuo que presenta dicha discapacidad en un puesto de trabajo que sea acorde a sus competencias. Para lograrlo deberá actuar en conjunto con la fundación que conozca a la persona en situación de discapacidad, pues la empresa deberá tener confianza y seguridad para contratar a aquel sujeto discapacitado. Además, hacen un hincapié en el hecho de que, respecto a la discapacidad psicosocial, no hay que hacer una adecuación a la planta física de la empresa, pues los ajustes que deberán hacerse son más de tipo social-laboral que físicos. Por esto último, es imprescindible la capacitación y preparación del personal que está vinculado a la empresa para que en el trato con estos individuos en situación de discapacidad no haya discriminación o subvaloración, que en ocasiones puede ser confundida con un sentimiento paternal hacia estos, lo que genera, en últimas, que no puedan ejecutar acciones por sí solos y que sean visto como incapaces por sus compañeros de trabajo y demás miembros de la empresa.

Igualmente, cabe añadir que para este tipo de discapacidad en imprescindible conocer las condiciones intralaborales, cuya definición trae Hernández (2014) de la siguiente forma: "Se entiende que las condiciones intralaborales son aquellas características del trabajo y de su organización que influyen en la salud y bienestar del individuo" (p. 20). Ahora bien, estas abarcan aspectos, respecto de las personas con diversidad funcional, tales como: la participación activa en los procesos internos y externos de la empresa; una real inclusión en los procesos de inducción y capacitación; la igualdad en los derechos laborales, como el pago del salario justo y adecuado; el propiciar la comunicación asertiva y efectiva por medio de canales, herramientas y mecanismos que lo hagan posible; y, que cuenten con la información necesaria sobre aspectos físicos, ambientales, responsabilidades, condiciones de trabajo (jornada, salario, etcétera) y los beneficios que puede adquirir por conceptos determinados por la empresa (López et al., 2017).

Durante el período de trabajo de la Ministra del Trabajo (20162017) Clara López Obregón, se presentó la Guía para el proceso de 
inclusión laboral de personas con discapacidad, en la cual ofrece, además de la clasificación de Agudelo et al (2017), una clasificación llamada discapacidad múltiple, la cual consiste en que una persona posee más de una afectación en sus capacidades. Como ejemplo de la anterior se pueden mencionar la sordoceguera y la parálisis cerebral. Por un lado, la sordoceguera trata de la presencia de deficiencias en una misma persona tanto en el sentido visual como en el auditivo. En consecuencia, limita la comunicación, el acceso a la información y la orientación. Por otro lado, se encuentra la parálisis cerebral, que consiste en un conjunto de alteraciones, que involucran el cerebro y el sistema nervioso, con lo que se afecta a la persona en el aprendizaje, el movimiento, llegando a permear otros sentidos como el visual. Según un artículo de National Institute of Neurological Disorders and Stroke (NINDS, 2007), se podría entender a la parálisis cerebral como un trastorno o alteración neurológica presentada normalmente en la infancia, que afecta de manera permanente el movimiento corporal y la coordinación muscular. Está, por lo general es causada por daños que ocurren en el cerebro en desarrollo que limitan la función del cerebro de controlar la capacidad de movimiento, postura y equilibrio.

En relación con la sordoceguera, se trae a colación a la tiflotecnología, como aquella dirigida, especialmente, a personas con discapacidades visuales, auditivas o ambas. Según la Organización Nacional de Ciegos Españoles (ONCE, 2016), “[...] la tiflotecnología funciona como tecnología especializada en facilitar la comunicación por parte de personas con deficiencias auditivas, visuales o ambas; permitiéndoles usar las tecnologías que propician la adquisición de información, como un instrumento esencial para la integración laboral" ( $p$. 3). Es importante precisar que se deben tener en cuenta, en cuanto a los ajustes razonables para esta discapacidad, dos aspectos como lo son: el tacto y la síntesis de voz adaptada en velocidad, volumen y tono. Así, se tienen los siguientes ejemplos: "[...] implantes cocleares, equipos de FM o audífonos con la conectividad pertinente [...] el uso del sistema Braille, siempre se recomendará, pues el Braille garantiza la correcta recepción de información” (ONCE, 2016, pp. 4-5). 
En cuanto a los ajustes razonables para el caso de una persona con parálisis cerebral, se puede incorporar el denominado sistema cerebro-ordenador. Esto permitirá identificar las respuestas del trabajador en forma de señales, que facilitan la recepción de la información por parte de los demás trabajadores del campo laboral. Es un implemento que ayuda a personas con deficiencias severas tanto en la comunicación como en el movimiento.

Es un dispositivo que permite establecer una comunicación con el mundo externo a partir de la actividad eléctrica cerebral sin la ayuda de los nervios periféricos o de la actividad motora. En especial, promete ser de gran ayuda a aquellas personas que sufren de discapacidades motoras severas [...] por ejemplo para el control y manejo de una silla de ruedas eléctrica (García y Gentiletti, 2008, p. 27).

De la misma manera que las demás clasificaciones de la discapacidad, no solo los cambios físicos en la empresa serán suficiente, sino que al mismo tiempo las buenas relaciones que se tendrán con los compañeros de trabajo serán esenciales para una atmósfera adecuada. Así, la concientización y la formación se dan en el día a día laboral por medio de la palabra y de aquellas observaciones de compañeros, jefes y personas con diversidad funcional los cuales logran crear diálogos de respeto y confianza (López, et al., 2017, p. 13). Es de precisar algunas conductas para dirigirse a las personas que tienen este tipo de diversidad funcional. Es necesario hablarles directamente a ellos con lenguaje sencillo y calmado, sentarse de frente, mirándose cara a cara a la misma altura [...] sus palabras pueden ser lentas así que es fundamental tener paciencia para escucharlos, no intentar adivinar ni interpretar (Asociación Granadina de Atención a Personas con Parálisis Cerebral-ASPACE, 2004).

Además, los compañeros en el ambiente laboral deben favorecer la autonomía personal del trabajador con diversidad funcional. En este caso, aquel que tiene parálisis cerebral, esto debe darse, en el nivel que puedan desarrollarse las habilidades diversas que les son propias a las personas en situación de discapacidad. 


\section{Una revisión a la situación jurídica}

de los ajustes razonables en Colombia

Actualmente, se identifica un asunto de vital importancia relacionado directamente con el colectivo de personas con diversidad funcional, vistos como sujetos de derecho que requieren garantías que permitan su desenvolvimiento de manera adecuada y en igualdad de condiciones en el campo laboral. Por ello, adquieren importancia dos aspectos: El principal es el modelo social enfocado en derechos, y el segundo, son los Derechos Humanos; ambos han sido la base de la normatividad actual vigente relacionada con la protección de los derechos de las personas con diversidad funcional. Además, otorgaron deberes y obligaciones a los estados y a la sociedad en general; en cuanto, al desarrollo de figuras cuyo entendimiento e implementación harán posible el ejercicio laboral del colectivo de personas en situación de discapacidad.

El ordenamiento jurídico en Colombia contempla diversidad de leyes y decretos que centran su atención en la protección e inclusión de las personas que padecen algún tipo de discapacidad ya sean físicas, mentales, intelectuales, sensoriales e incluso mixtas, tales como la Ley 361 (1997), por la cual se establecen mecanismos de integración social de las personas con discapacidad, aunque esta ley no menciona los ajustes razonables directamente; permanece en ella, una intención indirecta de acudir a los ajustes razonables como una necesidad esencial de la sociedad. Pues, la Ley 361 (1997, art. 2) señala que el Estado debe garantizar y velar por que en su territorio no prevalezca la discriminación sobre persona alguna, por circunstancias físicas, psíquicas, sensoriales, fisiológicas, etc.

Por otra parte, la Constitución Política Nacional (1991), en los artículos 13, 47 y 54 les brinda una especial protección constitucional como sujetos de derecho a las personas con diversidad funcional. De manera, que prevalezca el derecho al trabajo y las obligaciones estatales como lo señala la Corte Constitucional en la Sentencia T-933 (2013), cuyo magistrado ponente fue Jorge Ignacio Pretelt Chaljub, en la cual se indica que "Obligaciones específicas y prefe- 
rentes del Estado en adopción de medidas de inclusión y acciones afirmativas para evitar discriminación y garantizar derechos fundamentales" (p. 3).

Por otra parte, se encuentra el Decreto 2011 (2017), el cual menciona la implementación de ajustes razonables por parte de las empresas, como forma de inclusión de la población. De manera, que se facilite su acceso a los beneficios respectivos que se otorgan por cumplir dicha inclusión laboral a las personas con diversidad funcional. Además, se encuentra la Ley 1346 (2009), mediante la cual, se aprueba la convención sobre los derechos de las personas con discapacidad y se refiere directamente al reconocimiento y normativización de implementar ajustes razonables en todos los ámbitos, como el laboral, educativo, entre otros.

También, se encuentra la Ley Estatutaria 1618 (2013), por medio de la cual se establecen las disposiciones para garantizar el pleno ejercicio de los derechos de las personas con discapacidad, esta ley enfatiza en la aplicación de ajustes razonables y explica aspectos relacionados con ellos; y por último, está la Ley 1996 (2019), elimina la interdicción y establece el régimen de capacidad legal para las personas con discapacidad para mayores de edad, normativiza e incluye los ajustes razonables al ámbito del proceso judicial.

Pese a existir, toda esta normatividad sobre la implementación de ajustes razonables en el ámbito laboral no existe claridad y hay muchos vacíos de información sobre su aplicación. Lo cual, es evidencia de la falta de desarrollo, interpretación y precisión jurídica en el uso de los ajustes razonables que se deberán realizar dentro de una empresa. Por ejemplo, se ha identificado a la carga económica excesiva de la aplicación de los ajustes razonables como único límite o excepción que puede alegar el empleador para eximirse de dicha carga. En consecuencia, se sobreentiende que si un empleador se niega a dicha obligación no podrá ser considerado como discriminatorio frente al trabajador con diversidad funcional que lo solicita o para el cual se solicitó el ajuste. Sin embargo, no se han definido criterios para entender qué implica "una carga desproporcionada o excesiva" (ONU, 2006). 
De esta forma, la sistematización de la información relacionada con los ajustes razonables representa una de las virtudes que posee la investigación que presenta una metodología documental. Es necesario que el desarrollo de este tema se presente, al menos, como un acercamiento a su tratamiento en el contexto internacional enfocando algunos aspectos al contexto nacional colombiano. Si bien es cierto, en el ordenamiento jurídico colombiano se poseen los mecanismos para hacer exigible la implementación de ajustes razonables en una empresa, cuando así se requiera y se tenga los insumos o recursos para ello, no se cuenta con el conocimiento adecuado sobre los mismos, tanto por la parte trabajadora como de los empleadores. En ese sentido, es de resaltar que para el derecho colombiano no es ajena la obligación constitucional y la que deriva del bloque de constitucionalidad, acerca de la protección de las personas con diversidad funcional. Por ende, el que haya investigaciones académicas, científicas, o de reflexión sobre un mecanismo de inclusión laboral y de garantía de derechos fundamentales como a la igualdad y a la vida digna, se hace lógico y pertinente, a las luces de una sociedad que está en constante progreso y evolución.

$\mathrm{Al}$ área del conocimiento jurídico se le aporta la recopilación de aspectos claves para conocer a los ajustes razonables y, si se le reconoce su relevancia en el campo del derecho laboral nacional, se puede llegar a crear una norma jurídica que condense todos esos aspectos, por medio de la cual se abra paso a una verdadera exigibilidad de materializar esta estrategia dentro del sector empresarial de Colombia.

En este mismo sentido, se logró precisar los límites de los ajustes razonables. Cabe resaltar que es escasa la información en la literatura nacional, así como lo es en la normatividad jurídica interna respecto a señalar los límites o situaciones en las cuales las modificaciones o adaptaciones en la empresa no constituyen ni deben entenderse como obligatorias para la misma, tratándose de los que se necesiten para lograr la inclusión laboral de personas con diversidad funcional. Motivo por el cual, a través de la literatura internacional es posible identificar limitaciones a la obligación 
de implementar ajustes razonables en los puestos de trabajo para personas con diversidad funcional, para fomentar un desarrollo nacional amplio. Entre los límites se encuentran la razonabilidad como control de exigencias y la carga excesiva o desproporcionada.

Ahora bien, el primero de los límites señalados anteriormente, busca ser un orientador que facilita reconocer el grado de importancia que tiene la implementación de un ajuste razonable específico, frente a los demás ajustes razonables que pueden aplicarse. La implementación de los ajustes razonables no necesariamente incluye la adopción de cualquier medida, sino solamente aquellas que tienden a ser razonables dándole carácter de necesarios e indispensables para el ejercicio del cargo que va a ejercer el trabajador con diversidad funcional. Es decir, consiste en un estándar de valoración del ajuste, un prototipo de guía mediante la cual se identifica el nivel o el grado en el que debe aplicarse un ajuste razonable por parte del empleador en su empresa (Gutiérrez, 2018).

En cuanto a la segunda limitación de carga desproporcionada o indebida se entiende que está estrechamente relacionada con el aspecto económico que lleva consigo la implementación del ajuste razonable en la empresa, como también su mantenimiento, cuando así sea requerido; sobre esto se deberá tener una claridad en la situación económica de la empresa, y en fuentes que la puedan respaldar o financiar, con el objetivo de que no haya una carga desproporcionada en el componente económico de la misma. Es decir, consiste en el coste que implican los ajustes, la capacidad de la empresa que está obligada a proporcionar esto mismo. Además, mirar el beneficio general, la financiación pública, con ayudas externa o internas de la empresa que pueda cubrir el ajuste (Organización Internacional del Trabajo-OIT, 2017). Con este, límite la obligación existe, pero el empleador podrá exonerarse de su obligación cuando alegue encontrarse frente a esta situación.

El objetivo, es ampliar los conceptos y no limitar la información solamente a los vacíos de la norma nacional colombiana, el cual, abarca como único límite el aspecto económico, sin un amplio desarrollo de este. Es en este punto, en el que para saber cuándo 
un ajuste razonable debe y puede ser implementado se necesita observar y analizar la existencia de una justificación equilibrada entre la obligatoriedad de la implementación del ajuste y el factor de viabilidad económica de la empresa. Es oportuno, hacer hincapié en que el Estado colombiano, conserva un deber jurídico nacional e internacional con la protección de los derechos de las personas con diversidad funcional que consiste en regular y desarrollar normativamente todas aquellas figuras necesarias, para generar seguridad jurídica en el trabajador desde un punto general.

En el ámbito laboral, los ajustes razonables y las personas con diversidad funcional encontrarán un punto en común adicional a la relación de necesidad que hay entre ambos. Dicho vínculo, se relaciona con esas funciones de la empresa, en las cuales, debe proporcionar condiciones adecuadas y ayudas necesarias al trabajador con diversidad funcional. Con el fin, de cumplir con el principio constitucional de igualdad, derecho al trabajo y a mantener condiciones dignas para laborar. En otras palabras, una empresa brinda una calidad de vida cuando en su ejercicio se guía de forma ética y se interesa por la comodidad de sus integrantes; fomenta la inclusión y diversidad en la fuerza laboral; posee esquemas para el desarrollo integral de los trabajadores y sus familias (Palomino y López, 2019). En este mismo orden de ideas, se entiende que la empresa debe cumplir con la responsabilidad social empresarial generando una calidad de vida dentro de esta misma, siendo esta última, fomentada por medio de la aplicación de estrategias de inclusión laboral, entre las cuales están: los ajustes razonables y las cuotas de reserva. Con las anteriores, se llegará a fomentar un ambiente donde ganen ambos extremos de la relación laboral y se les permita a las personas con diversidad funcional acceder a un trabajo en igualdad de oportunidades.

\section{Conclusiones}

Los ajustes razonables se han convertido en una acción afirmativa y estrategia de inclusión laboral adecuada para el tratamiento de la discriminación hacia las personas con diversidad funcional. 
Su importancia radica en que su variedad, flexibilidad y universalidad, que permite que se pueda aplicar en cualquier Estado que busque cerrar brechas de desigualdad entre sus miembros. Así las cosas, se ha llegado a las siguientes conclusiones:

1. Un ajuste razonable se puede entender como aquella adecuación o adaptación requerida en la empresa donde labora la persona con diversidad funcional, tanto en la estructura física de la misma, como en lo concerniente a la interacción humana dentro de ese mismo entorno laboral. No obstante, no podrán exceder el límite que impone la carga que implica la aplicación de dichos ajustes razonables en la compañía. Esto deberá darse en el marco jurídico de los derechos fundamentales de las personas con diversidad funcional, los cuales deberán ser ejercidos en un ambiente de igualdad constitucional y de inclusión efectiva y real en el puesto de trabajo.

2. Las discapacidades son de tipo: física, sensorial, intelectual, psicosocial y múltiple.

3. Los ajustes razonables se implementarán en relación directa con el tipo de discapacidad que posee el trabajador para el caso concreto.

4. El diseño y la accesibilidad universal precede al ajuste razonable, pues la inclusión se deberá obtener haciendo del espacio de que se trate uno con características que posibiliten a cualquier persona su desenvolvimiento sin barreras de ninguna clase.

5. El estado colombiano, no se ha nutrido de información suficiente, que brinde a la sociedad una mejor capacitación al momento de aplicar y brindar seguridad jurídica en la implementación de ajustes razonables en el ámbito laboral.

6. Existe inseguridad jurídica en los derechos de las personas en situación de discapacidad por la falta de conceptualización, criterio jurisprudencial nacional e, incluso, falta de ejemplificación a nivel nacional sobre los límites de la obligación de implementar ajustes razonables por parte el empleador en su empresa para personas con diversidad funcional. 
7. No hay bases claras y el señalamiento de un proceso que direccione o especifique cuándo la empresa no es apta para realizar cambios de tipo interactivo para personas en situación de discapacidad.

8. La doctrina nacional e internacional es la estructura sobre la cual se cimienta la claridad de la figura de los ajustes razonables y los límites para implementarlos en las empresas.

9. Las acciones afirmativas, los ajustes razonables y el diseño universal, son parte esencial de la inclusión laboral de personas con diversidad funcional. Con ellas, se busca un beneficio general de toda la mano de obra empresarial.

10. la implementación de los ajustes razonables es importante porque representa una expresión de equivalencia de garantías y derechos constitucionales.

11. El Estado de Colombia necesita reglamentar de forma específica la figura de los ajustes razonables en la normatividad y, además, debe gestionar por el diseño de proyectos o actividades coherentes que permitan garantizar, en forma efectiva, la inclusión laboral del colectivo de personas con diversidad funcional.

12. En el proceso de inclusión laboral deberán ser partícipes tanto el empleador, como la sociedad, el Estado y, especialmente, las personas que están a cargo del acompañamiento de los individuos pertenecientes al colectivo de personas en situación de discapacidad.

13. Los límites a la obligación de implementar ajustes razonables son: la razonabilidad como control de exigencia de implementar un ajuste razonable y la carga excesiva o desproporcionada. El primero límite elimina la posibilidad de existencia de una obligación por parte del empleador; y en el segundo, existe la obligación, pero el empleador está exonerado de su cumplimento.

14. Cuando el empleador señala encontrarse inmerso en alguno de los límites a la obligación de implementar el ajuste, no podrá ser entendido como discriminatorio para con el trabajador que solicite la implementación del ajuste razonable. 
Cuestión distinta es negar la implementación de estos cuando se cuenta con los medios para hacerlo, situación que, a la luz de la Convención sobre los Derechos de las Personas con Discapacidad (ONU, 2006, art. 2), se convierte en un acto de discriminación por razón de la discapacidad.

\section{REFERENCIAS}

Agudelo, M. L., Casas, E. L., Tovar, A. y Villadiego, E. (2017). Guía para la inclusión de personas con discapacidad en el ámbito laboral. [Trabajo de grado]. Universidad Sergio Arboleda, Bogotá, D.C., Colombia. Recuperado de https://repository. usergioarboleda.edu.co/handle/11232/1005

Appnotize UG. (2017). LetMeTalk: Talker SAAC,CAA,SAC. [App Androide]. Recuperado de https://play.google.com/store/ apps/details?id=de.appnotize.letmetalk\&hl=es_CO

Araque, F. y Suárez, O. (2017). Reflexiones teóricas y legales del adulto mayor y la discapacidad en Colombia. Jurídicas CUC, 13(1), 97-120. http://dx.doi.org/10.17981/juridcuc.13.1.2017.05

ASPACE. (2004). Libro-Guía Soy paralítico cerebral. [Online]. Recuperado de http://aspacegranada.org/descargas/Libroguia.pdf

Bolaños, E. R. (2016). La idea de los ajustes razonables como forma complementaria para conseguir la igualdad de las personas con discapacidad. Actualidad Jurídica, 8(1.0), 40-54. Recuperado de https://www.uninorte.edu.co/web/actualidadjuridica/octava-edicion

CNDH México. (2018). Los principales derechos de las personas con discapacidad. CNDH México. [Online]. Recuperado de https://www.cndh.org.mx/documento/los-principales-derechos-de-las-personas-con-discapacidad

García, E. y Gentiletti, G. (2008). Interfaz Cerebro Computadora (ICC) basada en el potencial relacionado con eventos P300: Análisis del efecto de la dimensión de la matriz de estimulación sobre su desempeño. Revista Ingeniería Biomédica, 2(4), 26-33. Recuperado de https://revistas.eia.edu.co/index.php/BME/article/view/51/51 
Gutiérrez, D. (2018). La obligación de realizar ajustes en los puestos de trabajo para personas con discapacidad: origen, evolución y configuración actual. Una perspectiva desde el derecho comparado y el derecho español. [Tesis Doctoral]. Universitat Autònoma de Barcelona, España. Recuperado de https://ddd.uab.cat/record/195372

Hernández, D. X. (2014). Caracterización de riesgos psicosociales intralaborales, extralaborales y evaluación del estrés en trabajadores del sector montajes de soldadura y tubería a las obras civiles en la empresa BHB Ingeniería S.A.S Yopal. [Trabajo de grado]. UNAD, Bogotá, D.C., Colombia. Recuperado de https://repository.unad.edu.co/handle/10596/2508

Ke, X. y Liu, J. (2017). Discapacidad Intelectual. En, J. M. Rey (ed.), Manual de Salud Mental Infantil y Adolescente de la IACAPAP (pp. 5-6). Ginebra: IACAPAP. Recuperado de https:// iacapap.org/content/uploads/C.1-Discapacidad-IntelectualSPANISH-2018.pdf

Lermen, D., Martínez, J. C. y Parra, A. (2013). Consultoría sobre la normatividad y propuesta de ajustes. [Online]. Recuperado de https://discapacidadcolombia.com/index.php/empleo-ydiscapacidad/31-consultoria-analisis-normatividad-y-propuesta-de-ajuste

López, A. M., Colorado, C. C., Bermúdez, C. P., Rico, D., Gómez, E., Mejía, J. A., Aristizábal, D. C. y Gallego, C. (2017). Inclusión Laboral de Personas con Discapacidad una Perspectiva desde la Gestión del Talento Humano. Medellín: Editorial Universidad de Antioquia. Recuperado de http:// bibliotecadigital.udea.edu.co/bitstream/10495/7019/7/LopezAngelica_2017_InclusionLaboralDiscapacidad.pdf

Mahecha, P. (2018). Los servicios de Formación para el trabajo como parte del modelo de inclusión laboral de personas con discapacidad "Pacto de Productividad". Bogotá, D.C.: Puntoaparte. Recuperado de https://agenciapublicadeempleo.sena.edu.co/Documents/MODELO\%20DE\%20 INCLUSI\%C $3 \% 93 \mathrm{~N} \% 20 \mathrm{LABORAL} \% 20 \mathrm{DE} \% 20 \mathrm{PERSO}$ NAS\%20CON\%20DISCAPACIDAD.pdf 
NINDS. (2007). Parálisis cerebral: Esperanza en la investigación. Bethesda: NIH. Recuperado de https://espanol.ninds.nih. gov/trastornos/paralisiscerebral.htm\#toc

OIT. (2017). Fomentando la diversidad y la inclusión mediante ajustes en el lugar de trabajo una guía práctica. Ginebra: OIT. Recuperado de https://www.ilo.org/wcmsp5/groups/ public/---ed_norm/---declaration/documents/publication/ wcms_560782.pdf

OMS. (2001). Clasificación Internacional del Funcionamiento, de la Discapacidad y de la Salud (CIF). [WHA54.21]. Recuperado de http://www.who.int/classifications/icf/wha-sp.pdf?ua=1

ONCE. (2016). Guía sobre Tiflotecnología y tecnología de apoyo para uso educativo. Introducción en el uso de la tecnología en la educación de personas sordociegas. [Online]. Recuperado de http://creena.educacion.navarra.es/web/ bvirtual/2018/09/26/guia-sobre-tiflotecnologia-y-tecnologia-de-apoyo-para-uso-educativo/

ONU. (2006). Convención sobre los Derechos de las Personas con Discapacidad y Protocolo Facultativo. [Online]. Recuperado de http://www.un.org/disabilities/documents/convention/ convoptprot-s.pdf

Palacios, A. (2008). El modelo social de discapacidad: orígenes, caracterización y plasmación en la Convención Internacional sobre los Derechos de las Personas con Discapacidad. Madrid: Cinca. Recuperado de https://www.cermi.es/sites/default/files/docs/colecciones/Elmodelosocialdediscapacidad. pdf

Palomino, B. y López, G. (2019). Responsabilidad social de empresas de ecoturismo, normativa y política pública en ciudad de México. Jurídicas CUC, 15(1), 353-382. http://dx.doi. org/10.17981/juridcuc.15.1.2019.14

República de Colombia. Asamblea Nacional Constituyente. (1991). Constitución Política. Gaceta Constitucional, (127). Disponible en http://babel.banrepcultural.org/cdm/ref/collection/ p17054coll26/id/3850 
República de Colombia. Congreso de la República. (agosto 26 de 2019). Por medio de la cual se establece el régimen para el ejercicio de la capacidad legal de las personas con discapacidad mayores de edad. [Ley 1996]. Diario Oficial: No. 51.057. Disponible en http://www.secretariasenado.gov.co/ senado/basedoc/ley_1996_2019.html

República de Colombia. Congreso de la República. (27 de febrero de 2013). Por medio de la cual se establecen las disposiciones para garantizar el pleno ejercicio de los derechos de las personas con discapacidad. [Ley Estatutaria 1618]. DO: 48.717. Disponible en http://www.secretariasenado.gov.co/ senado/basedoc/ley_1618_2013.html

República de Colombia. Congreso de la República. (31 de julio de 2009). Por medio de la cual se aprueba la "Convención sobre los Derechos de las personas con Discapacidad”, adoptada por la Asamblea General de la Naciones Unidas el 13 de diciembre de 2006. [Ley 1346]. DO: 47.427. Disponible en http://www.secretariasenado.gov.co/senado/basedoc/ ley_1996_2019.html

República de Colombia. Congreso de la República. (7 de febrero de 1997). Por la cual se establecen mecanismos de integración social de las personas con limitación y se dictan otras disposiciones. [Ley 361]. DO: 42.978. Recuperado de http://www. secretariasenado.gov.co/senado/basedoc/ley_0361_1997. html

República de Colombia. Corte Constitucional. (01 de febrero de 2017). Expediente D-11498. [Sentencia C-043]. Magistrado Ponente: Jorge Iván Palacio Palacio. Recuperado de https:// www.corteconstitucional.gov.co/relatoria/2017/C-043-17. htm

República de Colombia. Corte Constitucional. (09 de diciembre de 2013). Expediente T-3.918.176. [Sentencia T-933]. MP: Jorge Ignacio Pretelt Chaljub. Recuperado de https://www.corteconstitucional.gov.co/RELATORIA/2013/T-933-13.htm 
República de Colombia. Corte Constitucional. (21 de noviembre de 2010). Expediente LAT 352. [Sentencia C-293]. MP: Nilson Pinilla Pinilla. Recuperado de http://www.corteconstitucional.gov.co/RELATORIA/2010/C-293-10.htm

República de Colombia. Corte Constitucional. (10 de mayo de 2000). Expediente D-2600. [Sentencia C-531]. MP: Álvaro Tafur Galvis. Recuperado de https://www.corteconstitucional. gov.co/relatoria/2000/c-531-00.htm

República de Colombia. Presidencia de la República. (30 de noviembre de 2017). Por el cual se adiciona el Capítulo 2 al Título 12 de la Parte 2 del Libro 2 del Decreto 1083 de 2015, Reglamentario Único del Sector de Función Pública, en lo relacionado con el porcentaje de vinculación laboral de personas con discapacidad en el sector público. [Decreto 2011]. Diario Oficial: 50.433. Recuperado de http://es.presidencia.gov.co/normativa/normativa/DECRETO\%202011\%20DEL\%2030\%20DE\%20NOVIEMBRE\%20DE\%202017.pdf

Solano, E. (2019). Estabilidad ocupacional reforzada en Colombia: una mirada crítica desde la jurisprudencia. Juridicas CUC, 15(1). 47-68. http://dx.doi.org/10.17981/juridcuc.15.1.2019.02

Van, T. A. (2003). Dominación étnica y racismo discursivo en España y América Latina. Gedisa: Barcelona.

Yupanqui, A., González, M. Á., Llancalahuén, M. Quilodrán, W. y Toledo, C. (2016). Lenguaje, discriminación y discapacidad en el contexto educativo de Magallanes: Un enfoque de derechos humanos desde la terapia ocupacional. Magallania (Punta Arenas), 44(1), 149-166. https://dx.doi.org/10.4067/ S0718-22442016000100009

* Este artículo deriva de la investigación denominada: inclusión laboral y discapacidad: una revisión teórica y una caracterización. los casos de Santa Marta, Barranquilla y Cartagena. El grupo de investigación al que pertenece es Joaquín Aarón Manjarrez de la Universidad Sergio Arboleda (Santa Marta, Colombia). 
Kelly Viviana Aristizábal Gómez es Doctora en Derecho, Magíster en Derecho, especialista en Derecho Laboral, especialista en Derecho Público, abogada, directora del Departamento de Derecho Privado de la Universidad Sergio Arboleda sede Santa Marta, docente de pregrado y postgrado, miembro del grupo de investigación Joaquín Aarón Manjarrez, línea de Derecho Privado. https:/orcid. org/0000-0001-6087-4074

Orlando Rodríguez Buenahora es Estudiante de derecho, miembro activo del semillero de Derecho Laboral, monitor y docente auxiliar de la Universidad Sergio Arboleda (Santa Marta). https://orcid. org/0000-0002-4188-2009

Victoria Andrea Blanquiceth Ulloa es Estudiante de derecho, miembro activo del semillero de Derecho Laboral, monitor y docente auxiliar de la Universidad Sergio Arboleda (Santa Marta, Colombia). https://orcid.org/0000-0001-9249-5781 